\title{
Dynamical sensory representations establish a rapid odor code in a spiking model of the insect olfactory system
}

\author{
Rinaldo Betkiewicz ${ }^{1,2^{*}}$, Farzad Farkhooi ${ }^{1,2}$, Martin Paul Nawrot ${ }^{1,2,3}$ \\ From 24th Annual Computational Neuroscience Meeting: CNS*2015 \\ Prague, Czech Republic. 18-23 July 2015
}

In their natural environment, animals sense and evaluate olfactory cues of time-varying composition and concentration. Their olfactory pathways are adapted to the natural stimulus statistics, thus it is not surprising that odor processing is fast [1]. Honey bees, for example, learn to discriminate odors presented as short as $200 \mathrm{~ms}$ [2]. The neural odor code in these animals emerges within $50 \mathrm{~ms}$ after stimulus onset and neural representation changes dynamically during and after an odorant is present $[1,3]$. How is the insect olfactory system optimized to reliably estimate spatial and temporal aspects of the olfactory environment and what are the mechanisms behind rapid odor processing?

To investigate odor encoding at the Antennal Lobe $(\mathrm{AL})$ and the Mushroom Body (MB) level, we employ a simple phenomenological spiking network model of the honeybee olfactory system. The model implements a transformation from a low dimensional dense odorant representation in the AL to a high dimensional sparse representation in the MB. We demonstrate how information about the stimulus is present in both encoding schemes, by time resolved classification of neural activity.

Our model displays sparse and robust odor representation in the Mushroom Body [4]. Typically, less than $10 \%$ of the Kenyon Cell population is activated by an odor, with only 2-3 spikes at the odor onset (Figure 1A). $\mathrm{KC}$ spikes establish a rapid odor identity code at stimulus onset, while intrinsic adaptation currents provide a persistent and prolonged odor trace (Figure 1B). Our

\footnotetext{
* Correspondence: rinaldo.betkiewicz@bccn-berlin.de

'Theoretical Neuroscience / Neuroinformatics, Freie Universität Berlin, Berlin, Germany

Full list of author information is available at the end of the article
}

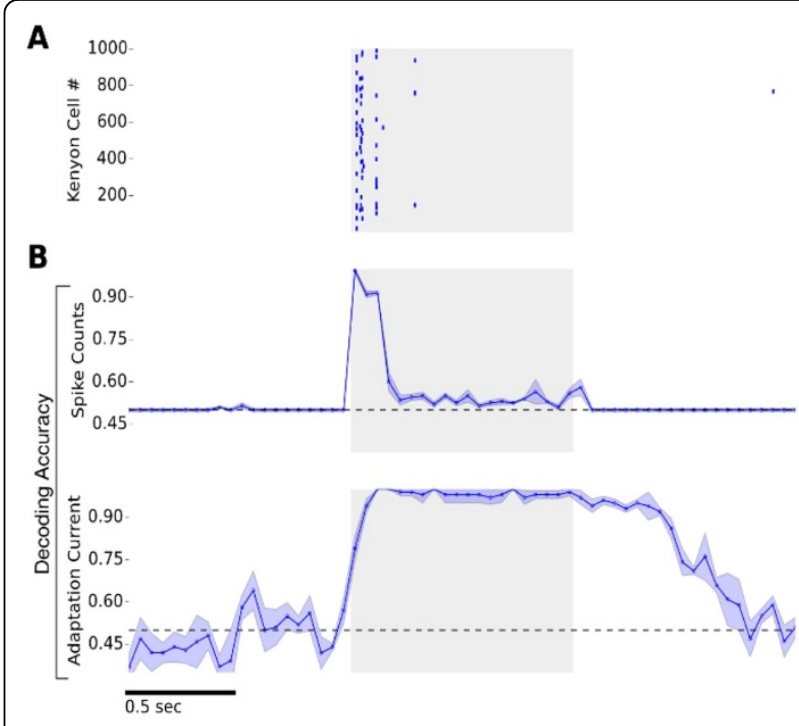

Figure 1 (A) Kenyon Cell spike raster plot. Stimulation is indicated by gray shading (B) Top: Decoding Accuracy given two odors (chance level: 0.5 ) as a function of time based on spike count estimates in 50ms time bins. Bottom: Decoding accuracy based on KC adaptation currents. Cellular adaptation levels provide a stable odor trace that persists as an odor afterimage.

approach allows us to investigate dynamical changes in odor representations and predict odor after images.

\section{Acknowledgements}

BMBF grant 01GQ0941 Insect Inspired Robots within the Bernstein Focus Learning and Memory (BFNL). Research Training Group Sensory Computation in Neural Systems (GRK 1589) funded by the German DFG.

\section{Authors' details}

'Theoretical Neuroscience / Neuroinformatics, Freie Universität Berlin, Berlin, Germany. ${ }^{2}$ Bernstein Center for Computational Neuroscience, Berlin, 
Germany. ${ }^{3}$ Computational Systems Neuroscience, University of Cologne, Cologne, Germany.

Published: 18 December 2015

\section{References}

1. Nawrot MP: Dynamics of sensory processing in the dual olfactory pathway of the honeybee. Apidologie 2012, 43:269-291.

2. Wright GA, Carlton M, Smith BH: A honeybee's ability to learn, recognize, and discriminate odors depends upon odor sampling time and concentration. Behavioral Neuroscience 2009, 123(1):36-43.

3. Strube-Bloss M, Herrera-Valdez M, Smith B: Ensemble response in mushroom body output neurons of the honey bee outpaces spatiotemporal odor processing two synapses earlier in the antennal lobe. PLoS One 2012, 7(11):e50322.

4. Farkhooi F, Froese A, Muller E, Menzel R, Nawrot MP: Cellular Adaptation Facilitates Sparse and Reliable Coding in Sensory Pathways. PLoS Computational Biology 2013, 9(10):e1003251.

doi:10.1186/1471-2202-16-S1-P174

Cite this article as: Betkiewicz et al.: Dynamical sensory representations establish a rapid odor code in a spiking model of the insect olfactory system. BMC Neuroscience 2015 16(Suppl 1):P174.

\section{Submit your next manuscript to BioMed Central} and take full advantage of:

- Convenient online submission

- Thorough peer review

- No space constraints or color figure charges

- Immediate publication on acceptance

- Inclusion in PubMed, CAS, Scopus and Google Scholar

- Research which is freely available for redistribution

Submit your manuscript at www.biomedcentral.com/submit 